\title{
Development of Amorphous/Microcrystalline Silicon Tandem Thin-Film Solar Modules with Low Output Voltage, High Energy Yield, Low Light-Induced Degradation, and High Damp-Heat Reliability
}

\author{
Chin-Yi Tsai ${ }^{1}$ and Chin-Yao Tsai ${ }^{2}$ \\ ${ }^{1}$ Department of Applied Physics, National University of Kaohsiung, Kaohsiung 811, Taiwan \\ ${ }^{2}$ Auria Solar, Da-Ye 1st Road 9, Sinshih, Tainan 74146, Taiwan \\ Correspondence should be addressed to Chin-Yi Tsai; cytsai@nuk.edu.tw
}

Received 26 January 2014; Accepted 3 February 2014; Published 16 March 2014

Academic Editor: Chien-Jung Huang

Copyright ( 2014 C.-Y. Tsai and C.-Y. Tsai. This is an open access article distributed under the Creative Commons Attribution License, which permits unrestricted use, distribution, and reproduction in any medium, provided the original work is properly cited.

In this work, tandem amorphous/microcrystalline silicon thin-film solar modules with low output voltage, high energy yield, low light-induced degradation, and high damp-heat reliability were successfully designed and developed. Several key technologies of passivation, transparent-conducting-oxide films, and cell and segment laser scribing were researched, developed, and introduced into the production line to enhance the performance of these low-voltage modules. A $900 \mathrm{kWp}$ photovoltaic system with these low-voltage panels was installed and its performance ratio has been simulated and projected to be $92.1 \%$, which is $20 \%$ more than the crystalline silicon and CdTe counterparts.

\section{Introduction}

Tandem amorphous/microcrystalline silicon (a-Si/ $\mu$-Si) thin-film solar modules with low output voltage have gained many attentions recently, because the high output voltage (around $100 \mathrm{~V}$ ) of regular modules will put a critical demand on the specifications of the associated balance of system (e.g., electrical connection cables) and it could not be compatible with the low output voltage (around $30 \mathrm{~V}$ ) of the mainstream products of crystalline silicon wafer-based solar modules. As a result, it is expected that the cost of balance of systems associated with the low-voltage a-Si $/ \mu$-Si thin-film solar modules could be lower than the regular high-voltage ones. In addition, low-voltage modules are more suitable for stand-along applications, for example, the conventional $12 \mathrm{~V}$ battery charging for consumer electronics.

An amorphous/microcrystalline silicon solar panel is usually laser scribed into cells and the cells are series connected. In order to achieve the low output voltage, the panel needs to be additionally laser scribed into several segments and the segments are then parallel connected. Conceptually, this segment laser scribing contributes only a few additional processes and the realization of the lowvoltage modules should be rather straightforward. However, in reality, there exist several technical challenges, especially in the mass production line. For example, the additional laser scribing will not only inevitably decrease the effective illuminated area and thus increase the area of dead zones, but also create many material defects along the edge of the scribed lines. The defects resulted from laser scribing will provide channels for leakage current and thus decrease the shunt resistance of solar modules. Therefore, the first technical challenge in developing the low-voltage modules will be to minimize the detrimental effects resulted from the laser scribing processes. Furthermore, because of the connection arrangements of series-connected cells and parallelconnected segments, the module performance inevitably will suffer from the mismatching effects results from the different physical characteristics of individual cells and segments. Due to this mismatching effect, the output current will be 


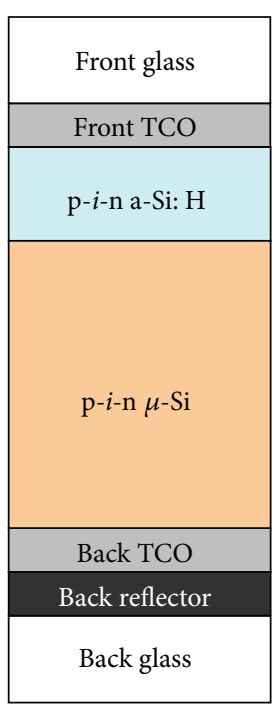

FIGURE 1: Schematic diagram of the structure of atandem amorphous/microcrystalline silicon thin-film solar cell.

determined by and suffered from the cell with the lowest short-circuit current and the output voltage will be determined by and suffered from the segment with the lowest open-circuit voltage. The mismatching effects caused by the different physical characteristics of cells and segments are mostly resulted from the nonuniformity of thin films due to the spatial variation of manufacture processes on largearea substrates, especially, the transparent-conducting-oxide (TCO) films grown by the low-pressure chemical vapour deposition (LPCVD) processes in which the nonuniformity of the film thickness could be over $20 \%$. How to improve the uniformity of manufacture processes and thus minimize the mismatching effects among cells and segments is another technical problem that needs to be resolved in order to develop the low-voltage solar modules. In the following, we will give a brief description on the developments of these key technologies and the performance of the low-voltage modules enabled by these technologies.

\section{Technologies}

In this work, the tandem amorphous/microcrystalline (also called as "micromorph") silicon thin-film solar modules are produced from the $60 \mathrm{MW}$ production line of Auria Solar [1-8]. The structure of a cell in a-Si/ $\mu$-Si thin-film solar modules is schematically shown in Figure 1. In general, the thickness of the front and back glasses is about $3.2 \mathrm{~mm}$, the back reflector $0.5 \mathrm{~mm}$, the a-Si:H cell layer $300 \mathrm{~nm}$, the $\mu$-Si cell layer $1400 \mathrm{~nm}$, the back TCO $1500 \mathrm{~nm}$, and the front TCO $1800 \mathrm{~nm}$. The manufacture processes of these modules are briefly outlined in Figure 2 in which a frontglass substrate go through the LPCVD TCO film growth, plasma-enhanced chemical vapor deposition (PECVD) a$\mathrm{S}: \mathrm{H} \mathrm{i}$ and $\mu$-Si film growth, and 3-step laser scribing to form the basic structure of solar cells and then metal ribbon wiring, back-reflector screen printing, abrasive blasting edge isolation, PV foil encapsulation, lamination, and junctionbox adhesion to form a finished module. The size of a panel is $1.3 \mathrm{~m} \times 1.1 \mathrm{~m}$. A module is usually laser scribed into 99 cells and its output voltage is regularly about $100 \mathrm{~V}$. To produce modules with lower output voltage, many technologies were researched, developed, and introduced into the production line. These technologies are required to ensure the efficiency of the low-voltage modules to be better than the regular ones. At the same time, the throughput and yield in every production process are demanded not to be compromised when introducing these technologies into the production line. These key technologies will be discussed in the following.

2.1. Passivation. A low-voltage panel needs to be laser scribed into several segments. These additional laser scribing lines function as edge isolations between two segments in a panel. The scribing line widths of segments are usually much larger than those of cells. As a result, segment laser scribing lines inevitably create many material defects along the edge of the scribed lines. The defects resulted from laser scribing will provide channels for leakage current and thus decrease the shunt resistance of modules. A passivation scheme for laser scribing lines, named as the moon technology, is designed and implemented to solve the problem of low shunt resistances resulted from laser scribing. The moon technology is denominated because the solar modules, after the treatment of this passivation technology, can effectively generate measurable power even at night under the feeble moon light. With the moon technology, the material defects resulted from laser scribing can be very effectively passivated and thus the shunt resistance can dramatically increase by one order of magnitude, for example, from original $2000 \Omega$ to more than $20,000 \Omega$. This will increase the module stabilized efficiency by an amount of more than $5 \sim 10 \%$. It has been investigated and reported that high shunt resistances will give monocrystalline silicon solar cells a much better low-light performance [9]. The similar conclusion can also been seen 


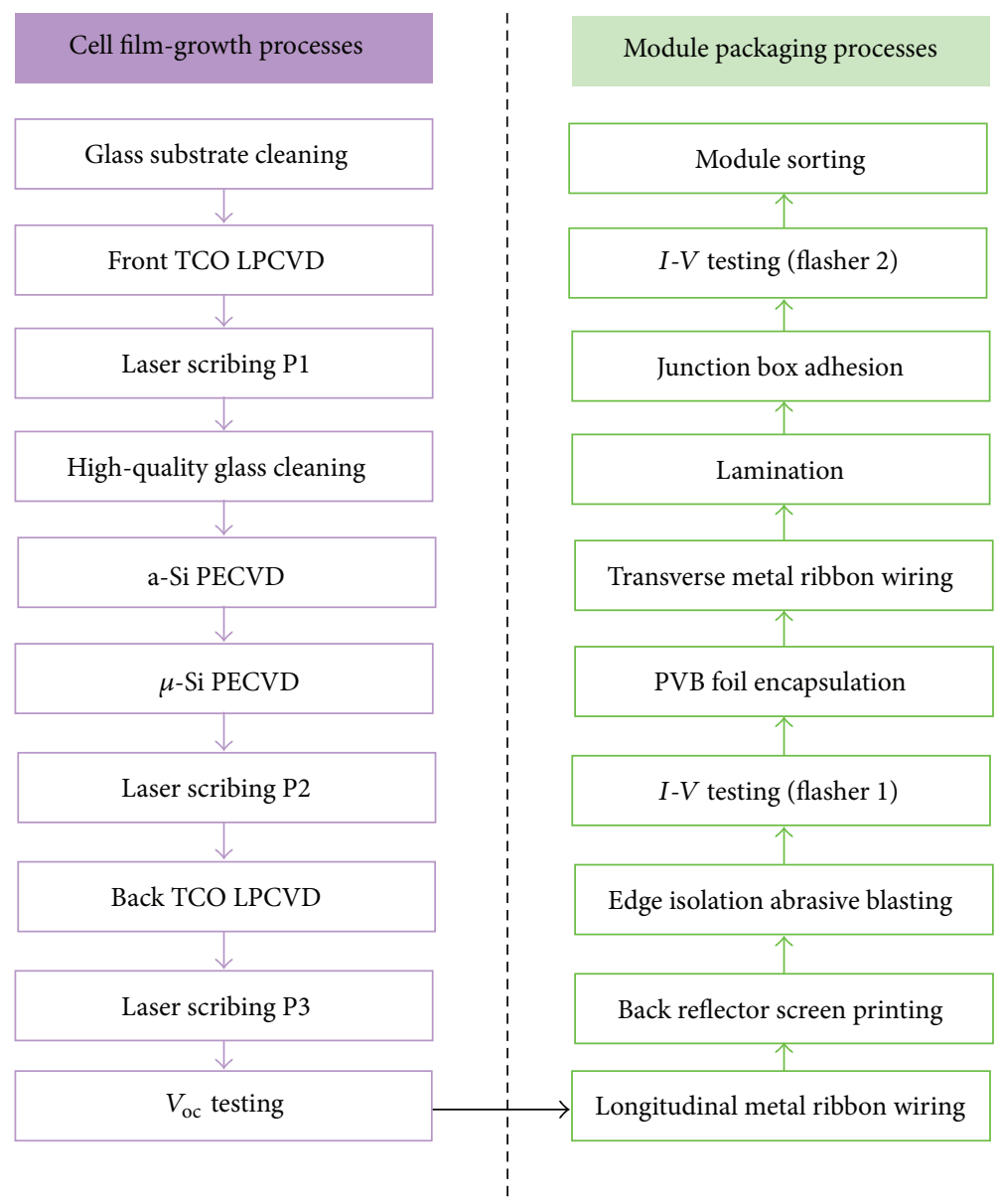

FIGURE 2: Schematic diagram of the flow of manufacture processes of tandem amorphous/microcrystalline silicon thin-film solar modules.

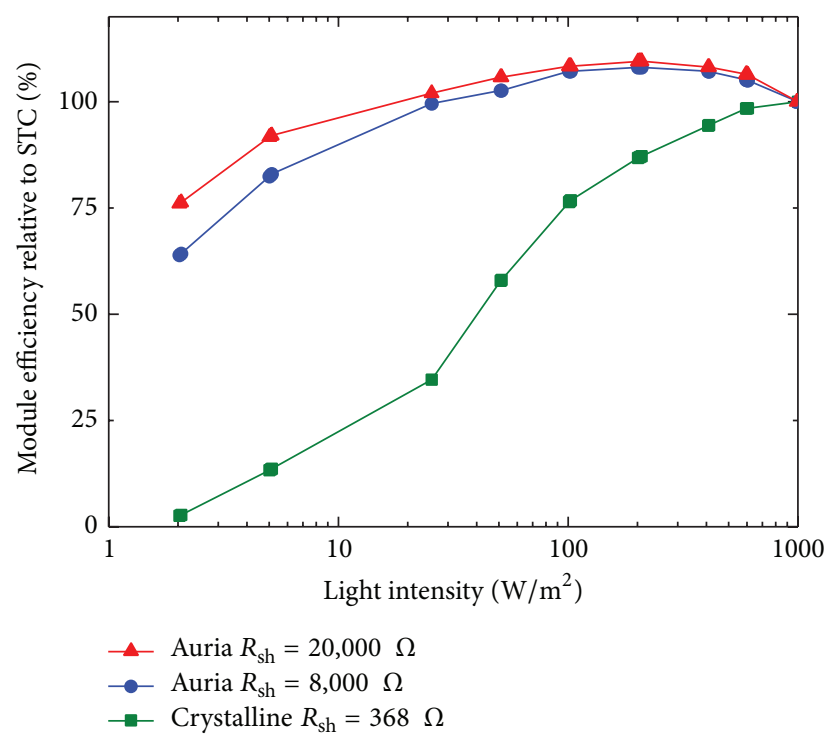

FIGURE 3: The module efficiency relative to standard testing condition (STC) as a function of the irradiance light intensity for two Auria thin-film and crystalline silicon modules with different shunt resistances $\left(R_{\mathrm{sh}}\right)$. 


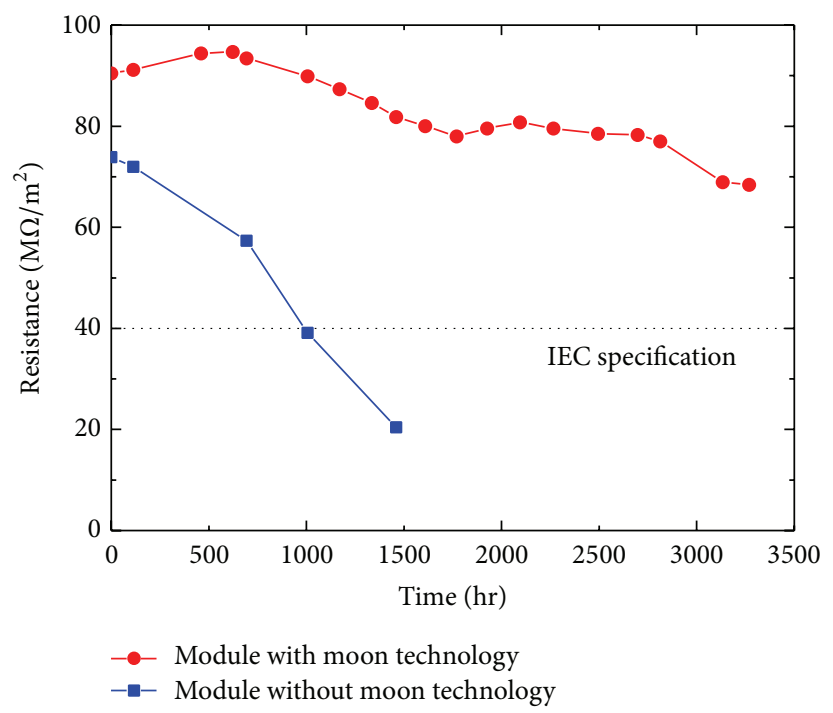

Figure 4: The resistance by module area as a function of the damp-heat testing time for modules with and without the moon technology passivation. Note that the dash line represents the minimum requirements of International Electrotechnical Commission (IEC) for the electric insulation in which the resistance should be larger than $40 \mathrm{M} \Omega$ per module area under the damp-heat testing condition.

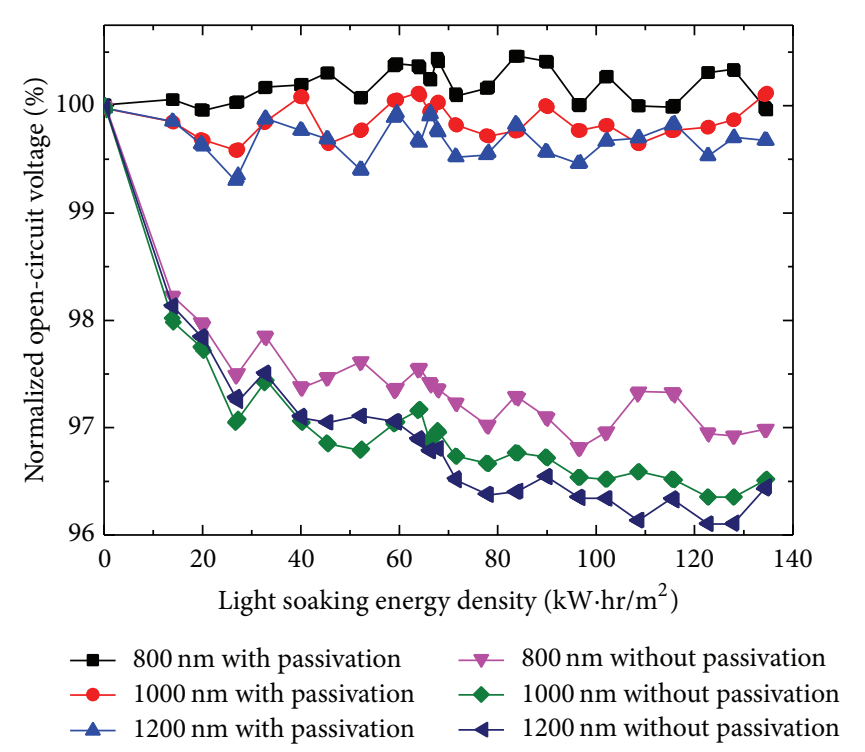

FIGURE 5: The open-circuit voltage $\left(V_{\mathrm{oc}}\right)$ as a function of the light soaking energy density for solar modules with different $i$-layer thickness of 800,1000 and $1200 \mathrm{~nm}$, and also with and without the moon technology passivation, respectively.

from our thin-film silicon modules as shown in the results of Figure 3. The enhancement on the low-light performance will increase the energy yield of modules by an amount of $10 \sim 15 \%$, according to our simulation. Furthermore, the material defects, such as microcracks, resulted from laser scribing not only provide channels for current leakage but also create permeative paths for water vapor to result in damp-heat degradation; therefore, technologies that can suppress the leakage current due to laser scribing will generally give modules a better performance under the damp-heat condition. The in-house damp-heat test $\left(1000\right.$ hour $85^{\circ} \mathrm{C}$ and $85 \%$ relative humidity) of our modules can even reach recorded over 3000 hours which is equivalent to 60 years damp-heat reliability, as shown in the results of Figure 4.

The passivation from moon technology not only minimizes the detrimental effects introduced by the laser scribing, but also surprisingly gives a beneficial effect of alleviating the light-induced degradation (LID) on silicon thin films. It has been observed that porous structures, such as cracks, exist in intrinsic $\mu c$-Si layers, which could lead to oxygen penetration and grain boundaries contamination and consequently cause the LID effects on fill factor and open-circuit 


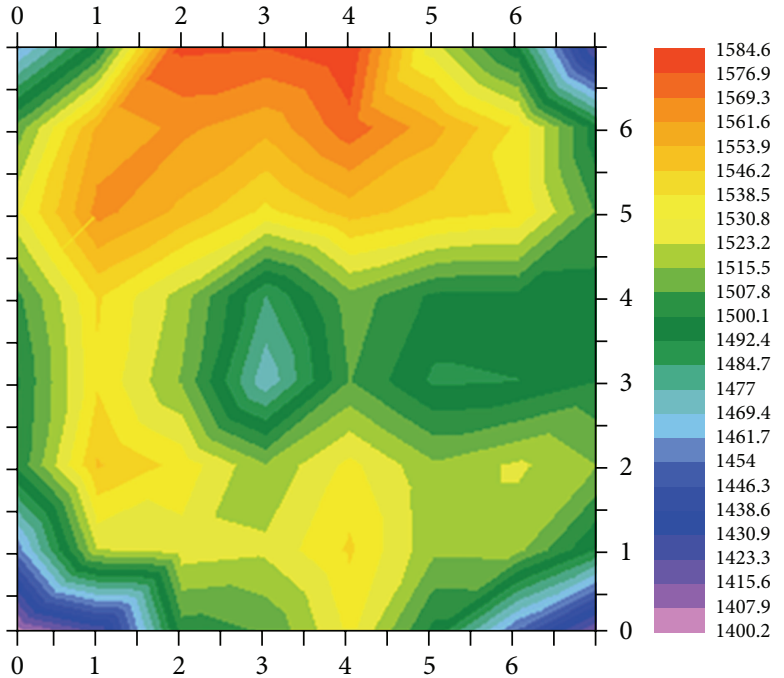

(a)

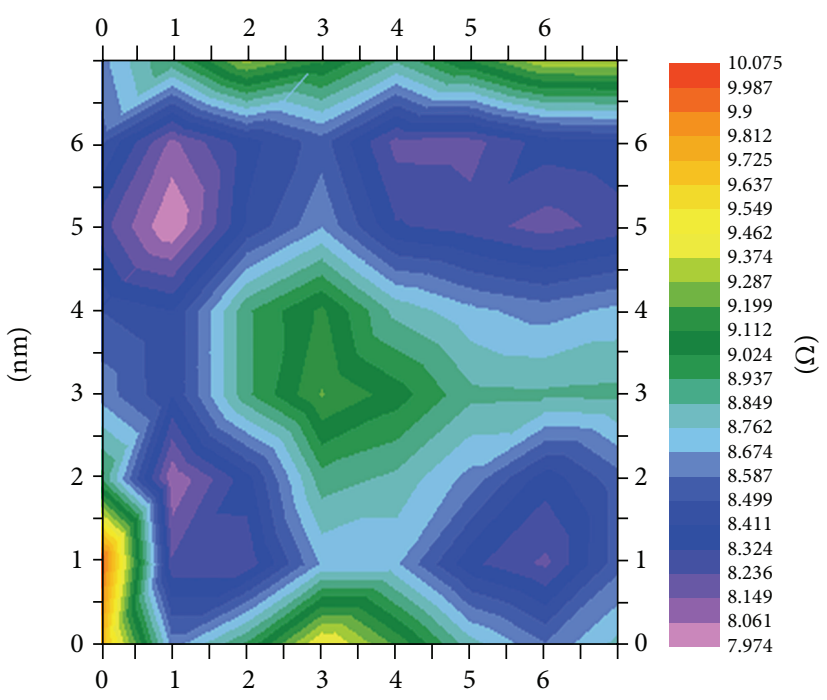

(b)

FIGURE 6: The (a) thickness and (b) resistance distributions of a TCO film represented by contour plot. The thickness and resistance uniformity is $2.8 \%$ and $11.64 \%$, respectively. Note that the unit on the scale of the color chart is nm in (a) and $\Omega$ in (b).

voltage of solar cells [10]. This fact has been verified by the light soaking experiments on the modules without the moon technology passivation, as shown in the results of Figure 5. On the contrary, for those modules with the moon technology passivation, the LID effects on the open-circuit voltage have been almost complete diminished. Therefore, it could be concluded that the moon technology passivation has successfully passivated the porous structures, such as cracks, in the intrinsic $\mu \mathrm{c}$-Si layers and thus alleviated their LID effects.

2.2. TCO Films. In a low-voltage module, the panel is laser scribed into cells and then into segments. The cells within a segment are series connected, while the segments are parallel connected. Because of such a connection arrangement, the module performance inevitably will suffer from the mismatching effects results from the different physical characteristics of individual cells and segments. For example, due to the mismatching effect, the output current will be determined by and suffered from the cell with the lowest short-circuit current. Similarly, the output voltage will be determined by and suffered from the segment with the lowest open-circuit voltage. The mismatching effects caused by the different physical characteristics of cells and segments are mostly resulted from the nonuniformity of thin films due to the spatial variation of manufacture processes. Since the size of the solar panel in this work is $1.3 \mathrm{~m} \times 1.1 \mathrm{~m}$, the mismatching effects resulted from the nonuniformity of thin films will become a critical problem, especially for the LPCVD boron doped $\mathrm{ZnO}$ TCO films.

In order to increase the uniformity of TCO films, the manufacture process are carefully redesigned from its original turn-key solution and the manufacture condition needs to be precisely controlled. Especially, the spatial distributions of growth temperature, gas flow, and pressure need to be constantly monitored and carefully controlled in order to ensure a better uniformity of the thickness and resistance of TCO films. Figure 6 shows the thickness and resistance spatial distributions of a TCO film. The thickness uniformity of TCO films in our production line can be as low as $2.8 \%$, which was dramatically improved from the original $20 \%$ specification. At the same time, the resistance uniformity of TCO films can be as low as $11.64 \%$, which is also significantly improved from the original $40 \%$ specification.

The surface morphology of TCO films needs to be carefully designed in order to optimize their light trapping function and minimize the interface defects between the TCO and Si films. For a TCO film of high haze, as shown in Figures 7(a) and 7(c), it has a larger and sharper grain morphology and thus a better light-trapping function, but it also creates more interface defects between the TCO and Si films. On the other hand, for a TCO film of low haze, as shown in Figures 7(b) and 7(d), it has a smaller and blunter grain morphology and thus a worse light-trapping function; nevertheless, it generates less interface defects between the TCO and Si films. The low-voltage solar modules in this work are designed with the optimal haze and thus have their maximum light-trapping function and minimum interface defects between the TCO and Si films.

2.3. Laser Scribing. In a low-voltage module, additional laser scribing lines are needed to form several segments in a panel. Usually, these segment-forming lines are much wider than the cell-forming lines in order to introduce good edge isolation between two segments; as a result, they will reduce the effective illuminated area of panels. In order to increase the effective illuminated area, the dead zone of laser scribing in our low-voltage module has been minimized to be as low as $150 \mu \mathrm{m}$ (as shown in Figure 8), which is significantly improved from the original $400 \mu \mathrm{m}$ specification. This result 


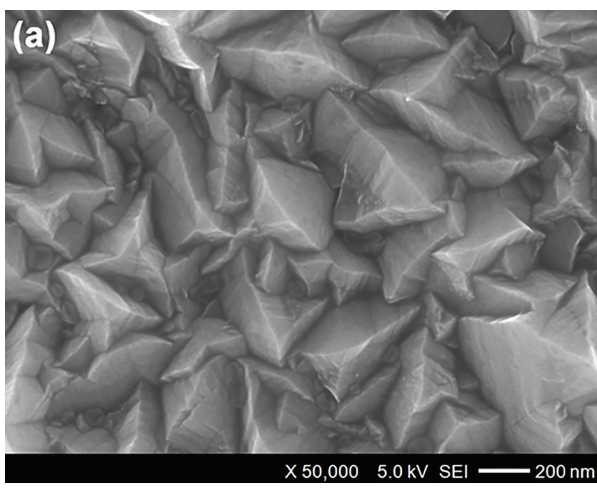

(a)

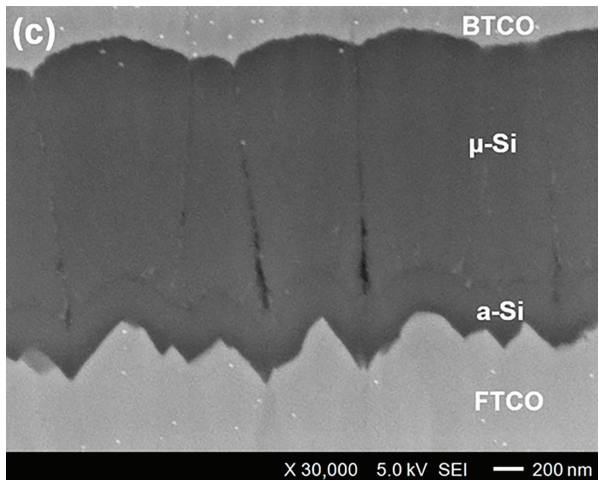

(c)

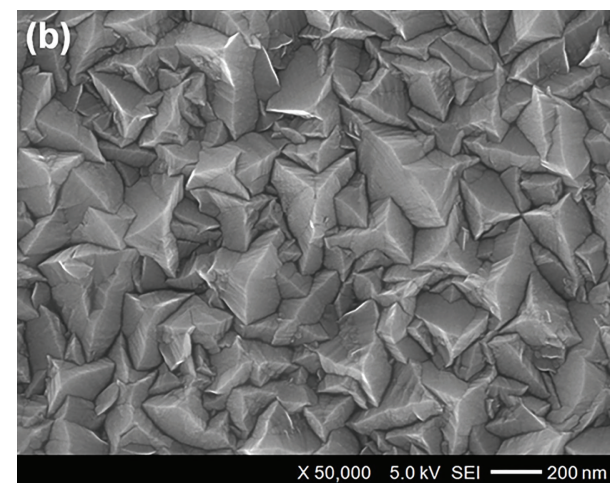

(b)

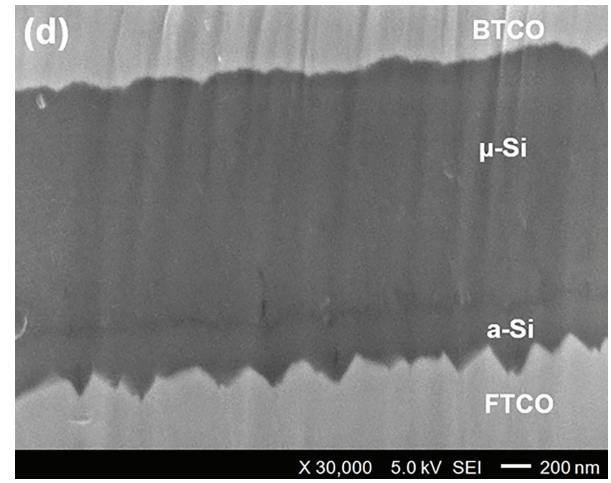

(d)

FIgurE 7: SEM top views of the front TCO in (a) a cell with high-haze TCO and (b) a cell with low-haze TCO. Their correspondent cross section views is given in (c) and (d), respectively.
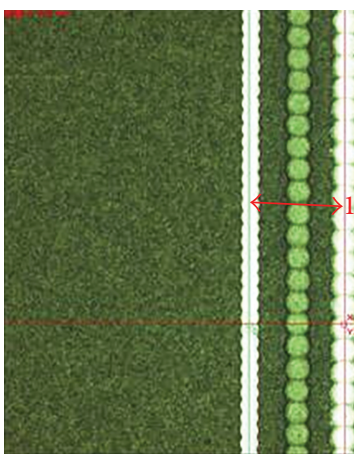

(a)

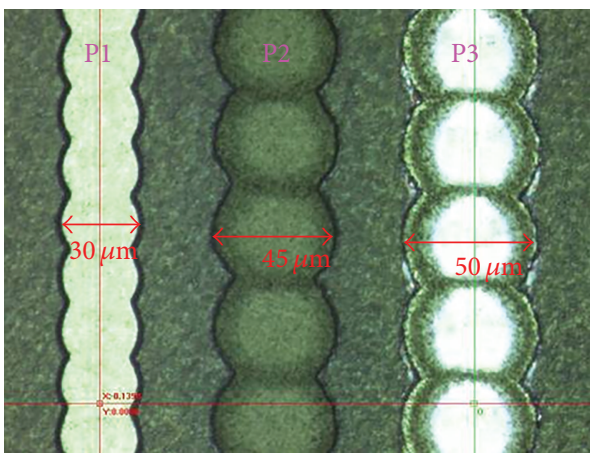

(b)

Figure 8: Three laser scribing lines, P1, P2, and P3, in a solar module. The dead zone is $150 \mu \mathrm{m}$.

was achieved by several major tunings in the peak power, focus, and pulse duration of laser sources from its original turn-key specifications.

Although the nonuniformities of TCO films have been reduced to be as minimum as possible, their effects on the physical characteristics of solar modules, such as short-circuit current, could still be demonstrated in the results of Figure 9, in which a $1.3 \times 1.1 \mathrm{~m}^{2}$ solar module is divided into 33 regions and the normalized short-circuit current decreases from $100 \%$ at the edge to around $95 \%$ at the center. In other words, the TCO film nonuniformity causes a 5\% mismatching effect on the short-circuit current. Taking this fact into consideration, two types of low-voltage solar modules were designed and developed: one is laser scribed into 128 cells and 2 segments while the other 138 cells and 4 segments (as schematically shown in Figure 10). It should be noted that the original high-voltage solar module are laser scribed into 99 cells and without any segment. The increase in the number of cells in the low-voltage solar module is designed to optimize their performance and minimize the mismatching effects. The output voltage of the formal one is designed to be around $30 \mathrm{~V}$ (named as LV30 modules) which is roughly 


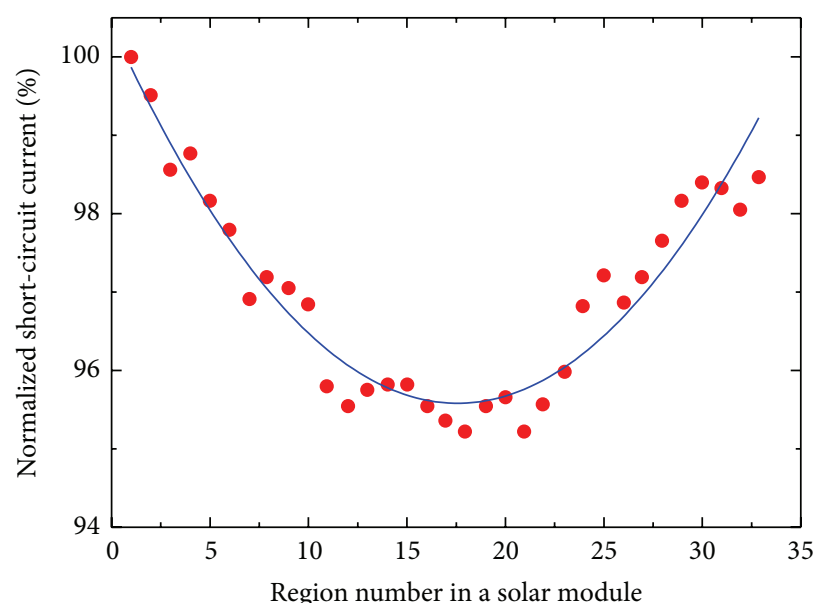

- Raw data

Fitting curve

FIGURE 9: Normalized short-circuit current distribution in a $1.3 \mathrm{~m} \times 1.1 \mathrm{~m}^{2}$ silicon thin-film solar modules divided into 33 regions.

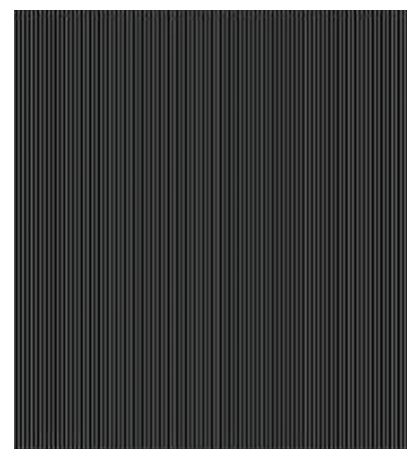

Regular (100 V)

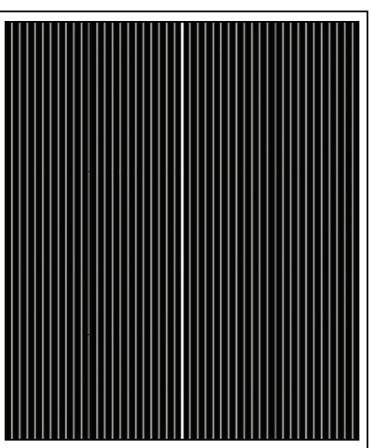

LV70

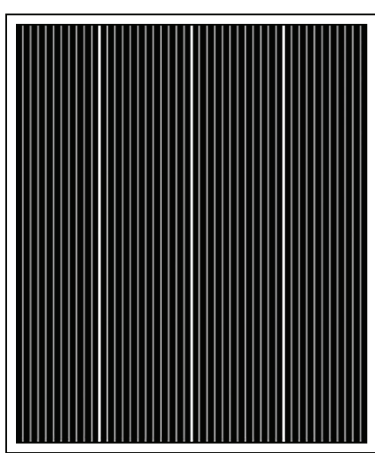

LV30

(a)

(b)

(c)

FIGURE 10: Schematic diagram of laser-scribed lines on (a) a regular module with 99 cells, (b) a $70 \mathrm{~V}$ low-voltage module (LV70) with 128 cells and 2 segments, and (c) a $30 \mathrm{~V}$ low-voltage module (LV30) with 138 cells and 4 segments.

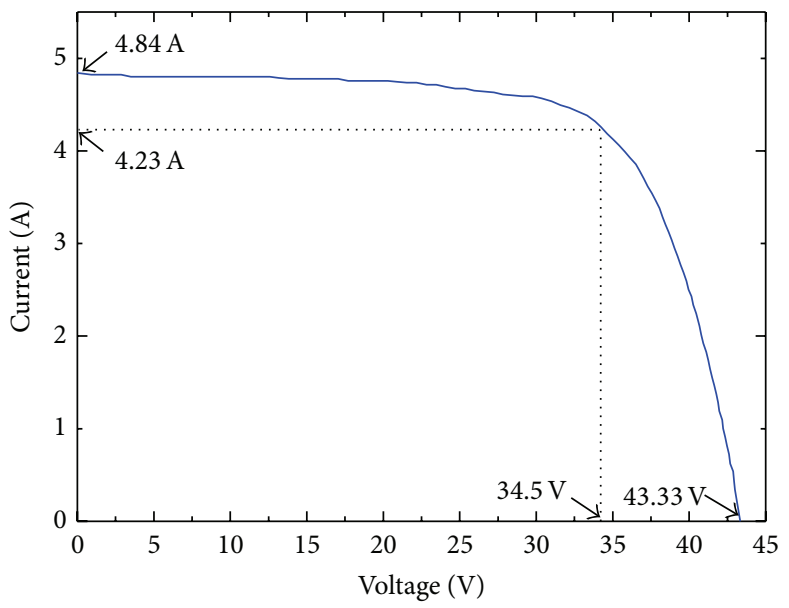

FIGURE 11: $I$-V curve of a $30 \mathrm{~V}$ low-voltage solar module (LV30) with open-circuit voltage $43.33 \mathrm{~V}$, short-circuit current $4.843 \mathrm{~A}$, maximum power voltage $34.5 \mathrm{~V}$, and maximum power current $4.23 \mathrm{~A}$. It should be noted that the $I-V$ curve gives the initial maximum output power 145.94 W, while the stabilized maximum output power is $130.4 \mathrm{~W}$ after the light-induced degradation. 


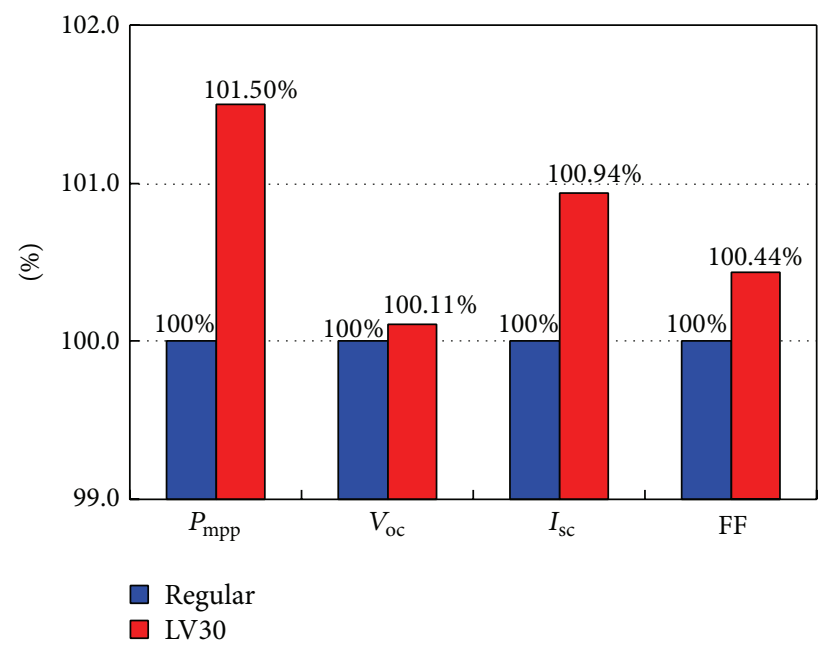

FIGURE 12: Comparison of maximum output power, open-circuit voltage, short-circuit current, and filled factor between a $30 \mathrm{~V}$ low-voltage silicon thin-film solar module (LV30) and a crystalline silicon wafer-based solar module.

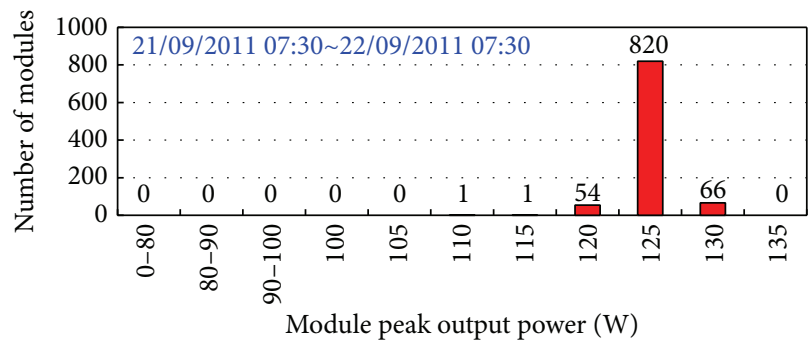

FIGURE 13: The distribution of power rating from a daily production record of LV30 modules in Auria Solar, where the produced modules are sorted according to their stabilized maximum output power.

correspondent to its counterpart of a typical crystalline silicon wafer-based solar module. On the other hand, the output voltage of the latter one is designed to be around $70 \mathrm{~V}$ (named as LV70 modules) which is approximately correspondent to its counterpart of a typical CdTe thin-film solar module. The performance of these low-voltage solar modules will be discussed in the following.

2.4. Lamination. In a low-voltage panel, metal ribbons are applied onto each individual segment. Different segments are then parallel connected by additional metal ribbons into the junction box. The ribbons on the individual segments will certainly result in uneven surface on the back side of the panel. This uneven surface will pose a serious problem for the lamination process. Therefore, the pressure, heat, and air flow need to be carefully designed and precisely controlled during the whole lamination processes to comply with the uneven surface from the additional metal ribbons of low-voltage modules. At the same time, the yield loss from lamination is still kept to be less than $1 \%$ even under the complicated layout topography of low-voltage modules. Most importantly, the throughput of lamination is required to be never compromised in the $60 \mathrm{MW}$ production line.

\section{Results and Discussion}

With the above technologies, two kinds of low-voltage tandem amorphous/microcrystalline silicon thin-film solar modules, $30 \mathrm{~V}$ and $70 \mathrm{~V}$, were successfully designed and mass produced in Auria's $60 \mathrm{MW}$ production line. Figure 11 shows the $I-V$ characteristics of a $30 \mathrm{~V}$ low-voltage module (LV30) with open-circuit voltage $V_{\mathrm{oc}}=43.33 \mathrm{~V}$, short-circuit current $I_{\mathrm{sc}}=4.843 \mathrm{~A}$, maximum power voltage $V_{\mathrm{mpp}}=34.5 \mathrm{~V}$, and maximum power current $I_{\mathrm{mpp}}=4.23 \mathrm{~A}$. Its initial maximum output power is $145.94 \mathrm{~W}$, while its stabilized maximum outpour power is $130.4 \mathrm{~W}$ after the effect of light-induced degradation. Compared with the correspondent crystalline silicon wafer-based solar module, the low-voltage module has better performance in all the aspects of its performance, such as maximum peak power, open-circuit voltage, short-circuit current, and filled factor, as shown in Figure 12.

The characteristic of the LV30 module is approximately correspondent to its counterpart of a typical crystalline silicon wafer-based solar module. A $70 \mathrm{~V}$ low-voltage solar module (LV70) is demonstrated with open-circuit voltage $V_{\mathrm{oc}}=92.6 \mathrm{~V}$, short-circuit current $I_{\mathrm{sc}}=2.25 \mathrm{~A}$, maximum power voltage $V_{\mathrm{mpp}}=71.3 \mathrm{~V}$, and maximum power current $I_{\mathrm{mpp}}=1.83 \mathrm{~A}$. The characteristic of the LV70 module is closely correspondent to that a typical CdTe thin-film 


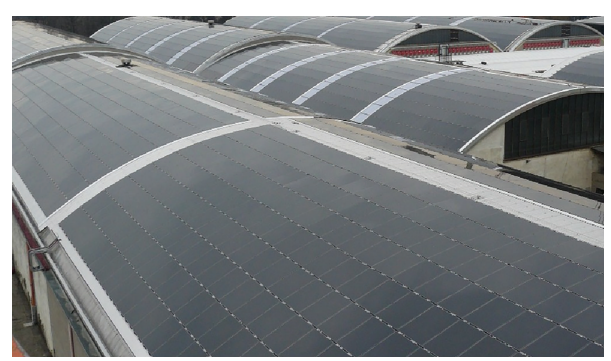

FIGURE 14: The $900 \mathrm{~kW}$ PV system with Auria’s high-performance low-voltage solar modules installed in an agriculture product distribution center near Verona of Italy.

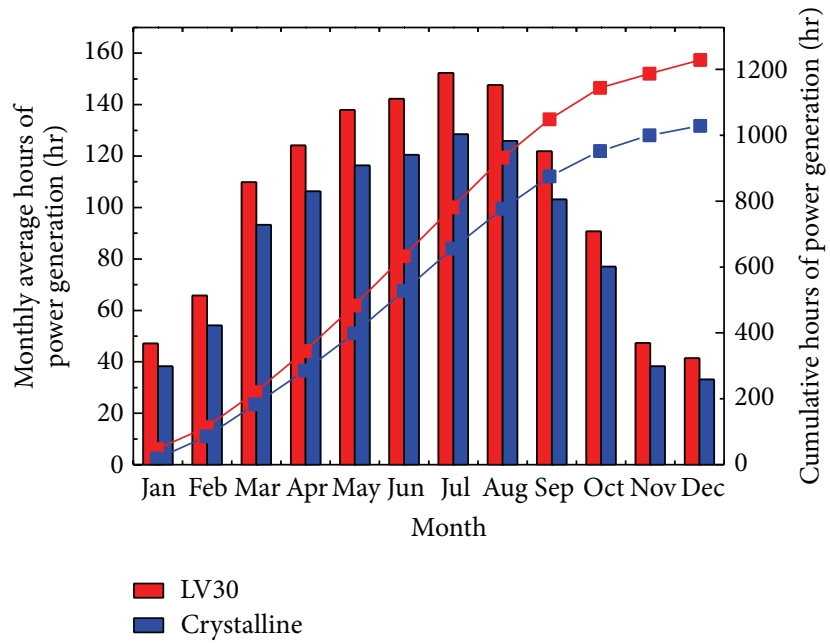

FIGURE 15: Simulation of the average hours power generation per month with the $900 \mathrm{~kW}$ LV30 PV system installed near Verona of Italy and its counterpart of a crystalline silicon solar module.

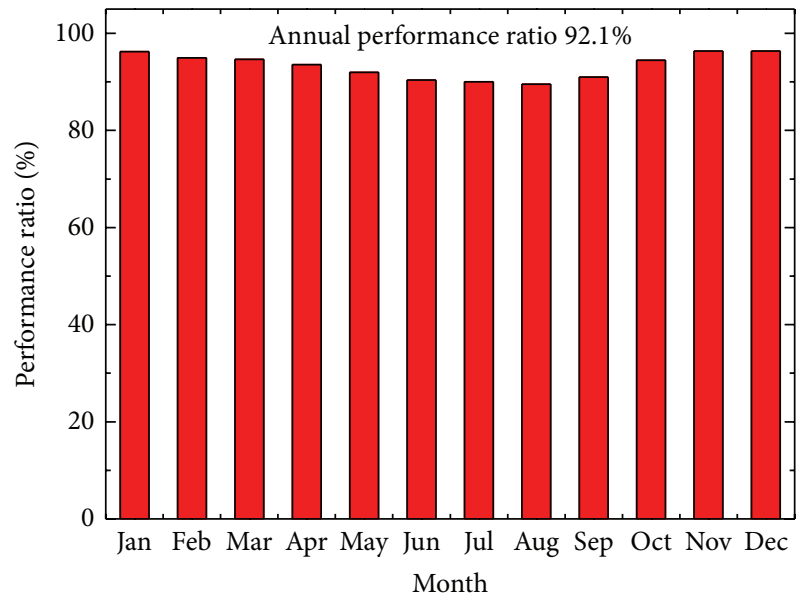

FigURE 16: Simulation of the performance ratio of the $900 \mathrm{~kW} \mathrm{LV30}$ PV system installed near Verona of Italy.

module. It should be noted that our low-voltage modules have been regularly mass produced and their very narrow power distribution (as shown in Figure 13) clearly demonstrates our superb technologies and excellent quality control.

A $900 \mathrm{~kW}$ PV system with these high-performance lowvoltage modules was installed in an agriculture product distribution center near Verona of Italy, as shown in Figure 14. The PV panels and inverters are Auria C125 (LV30 type) and SMA Sunny Mini Central $700 \mathrm{HV}$ and the total number of PV modules and inverters are 7200 and 120 units, respectively. According to simulation software PV syst 5.21 for PV systems, $20 \%$ more energy yield per year can be obtained from our $30 \mathrm{~V}$ low-voltage solar modules in comparison to that of the crystalline silicon counterparts, as shown in Figure 15. Its performance ratio (PR) has been projected to be $92.1 \%$ (as shown in Figure 16) which is better than our regular modules (87.2\% PR) and also much better than the crystalline silicon and CdTe counterparts (both around $83 \sim 85 \%$ PR). In other words, our low-voltage silicon thin-film modules would have energy yield much higher than crystalline $\mathrm{Si}, \mathrm{CdTe}$, and CIGS thin-film modules.

\section{Conclusion}

In short, low-voltage tandem amorphous/microcrystalline silicon thin-film solar modules with high energy yield, low light-induced degradation, and high damp-heat reliability have been successfully designed and mass produced. Several key technologies in passivation, transparent-conductingoxide films, and cell and segment laser scribing were researched, developed, and introduced into the production 
line to enhance the performance these low-voltage modules and narrow their distribution of power rating in mass production. It was demonstrated that low-voltage silicon thin-film modules would generate energy yield much higher than crystalline $\mathrm{Si}, \mathrm{CdTe}$, and CIGS thin-film modules. In addition, with their shorter energy payback time due to their low-temperature manufacture processes, low-voltage silicon thin-film modules have higher investment return ratio (IRR).

\section{Conflict of Interests}

The authors declare that there is no conflict of interests regarding the publication of this paper.

\section{Acknowledgments}

The authors would like to thank the help from all the colleagues in Auria Solar. This work is partially funded by the Bureau of Energy of Ministry of Economic Affairs and the National Science Council of Taiwan.

\section{References}

[1] H. Keppner, J. Meier, P. Torres, D. Fischer, and A. Shah, "Microcrystalline silicon and micromorph tandem solar cells," Applied Physics A: Materials Science and Processing, vol. 69, no. 2, pp. 169-177, 1999.

[2] A. Shah, J. Meier, E. Vallat-Sauvain et al., "Microcrystalline silicon and "micromorph" tandem solar cells," Thin Solid Films, vol. 403-404, pp. 179-187, 2002.

[3] J. Meier, S. Dubail, S. Golay et al., "Microcrystalline silicon and the impact on micromorph tandem solar cells," Solar Energy Materials and Solar Cells, vol. 74, no. 1-4, pp. 457-467, 2002.

[4] A. V. Shah, H. Schade, M. Vanecek et al., "Thin-film silicon solar cell technology," Progress in Photovoltaics: Research and Applications, vol. 12, no. 2-3, pp. 113-142, 2004.

[5] K. Yamamoto, M. Yoshimi, Y. Tawada, Y. Okamoto, and A. Nakajima, "Thin film Si solar cell fabricated at low temperature," Journal of Non-Crystalline Solids, vol. 266-269, pp. 1082-1087, 2000.

[6] K. Yamamoto, M. Yoshimi, Y. Tawada et al., "Large area thin film Si module," Solar Energy Materials and Solar Cells, vol. 74, no. 1-4, pp. 449-455, 2002.

[7] K. Yamamoto, A. Nakajima, M. Yoshimi et al., "A high efficiency thin film silicon solar cell and module," Solar Energy, vol. 77, no. 6, pp. 939-949, 2004.

[8] A. Nakajima, M. Gotoh, T. Sawada et al., "Development of thinfilm Si HYBRID solar module," Solar Energy Materials and Solar Cells, vol. 93, no. 6-7, pp. 1163-1166, 2009.

[9] G. E. Bunea, K. E. Wilson, Y. Meydbray, M. P. Campbell, and D. M. de Ceuster, "Low light performance of monocrystalline silicon solar cells," in Proceedings of the IEEE 4th World Conference on Photovoltaic Energy Conversion, vol. 2, pp. 1312-1314, Waikoloa, Hawaii, USA, May 2006.

[10] M. Python, D. Dominé, T. Söderström, F. Meillaud, and C. Ballif, "Microcrystalline silicon solar cells: effect of substrate temperature on cracks and their role in post-oxidation," Progress in Photovoltaics: Research and Applications, vol. 18, no. 7, pp. 491-499, 2010. 

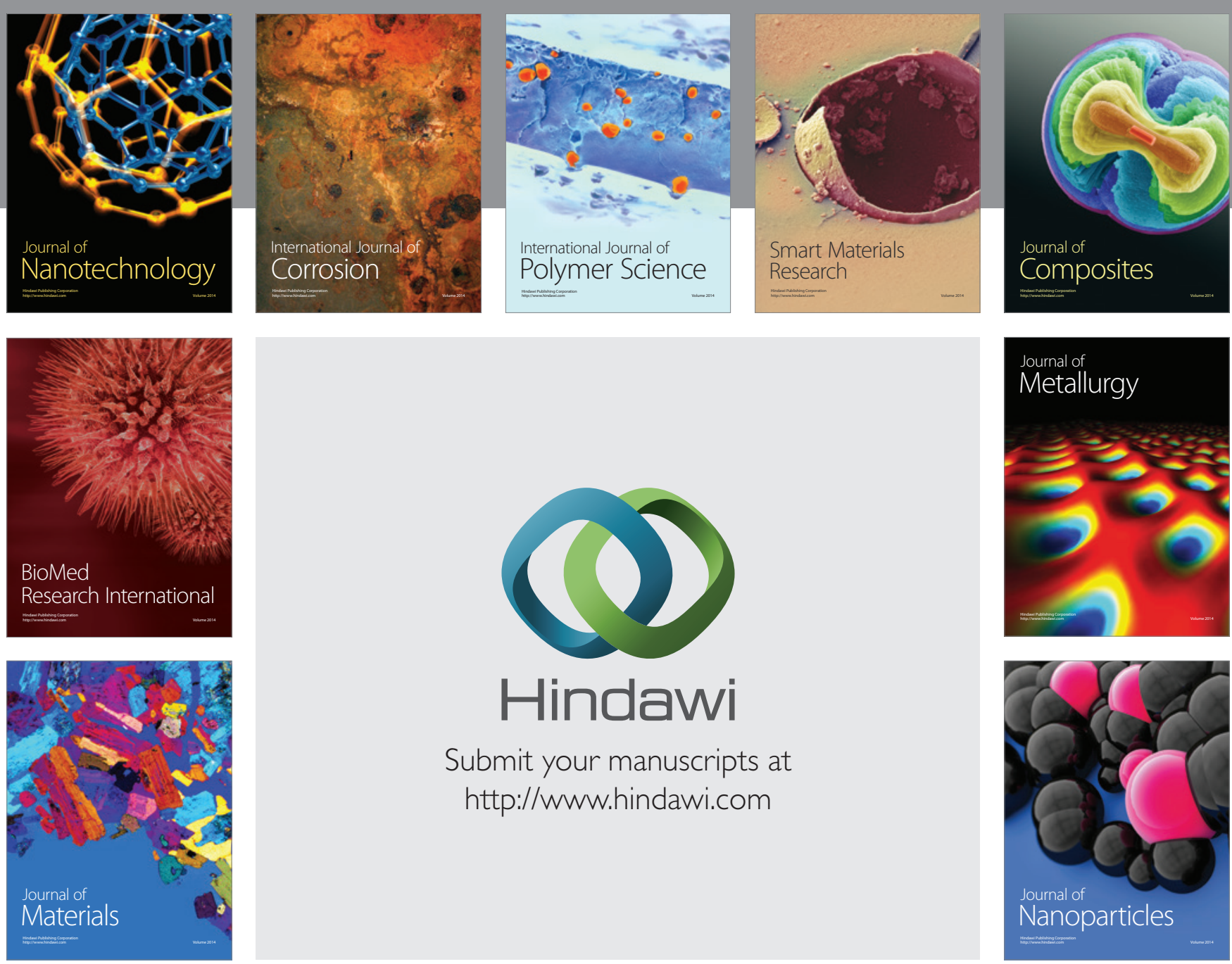

Submit your manuscripts at http://www.hindawi.com
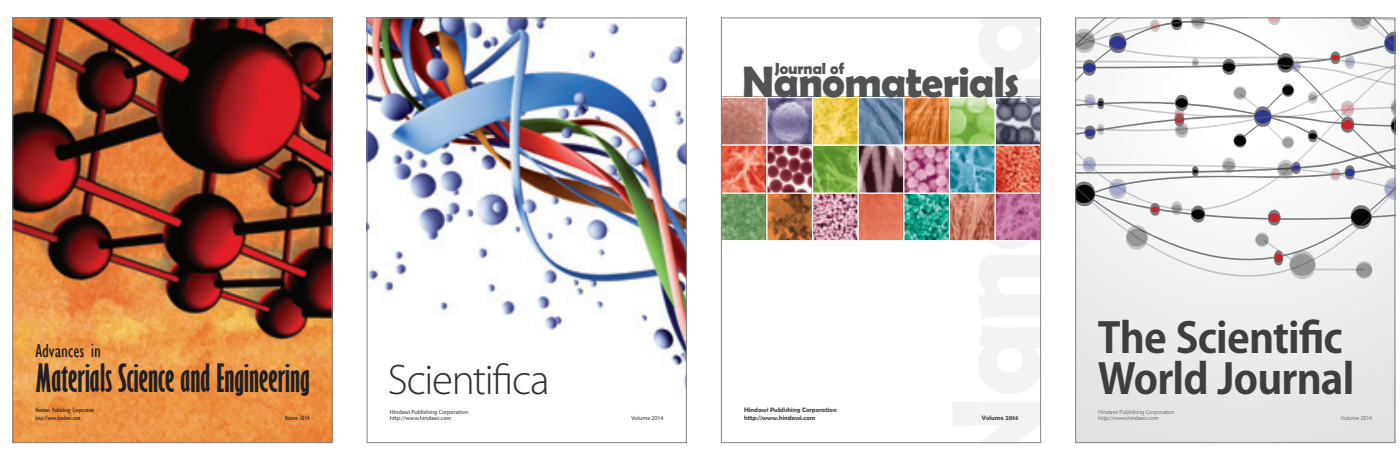

\section{The Scientific World Journal}
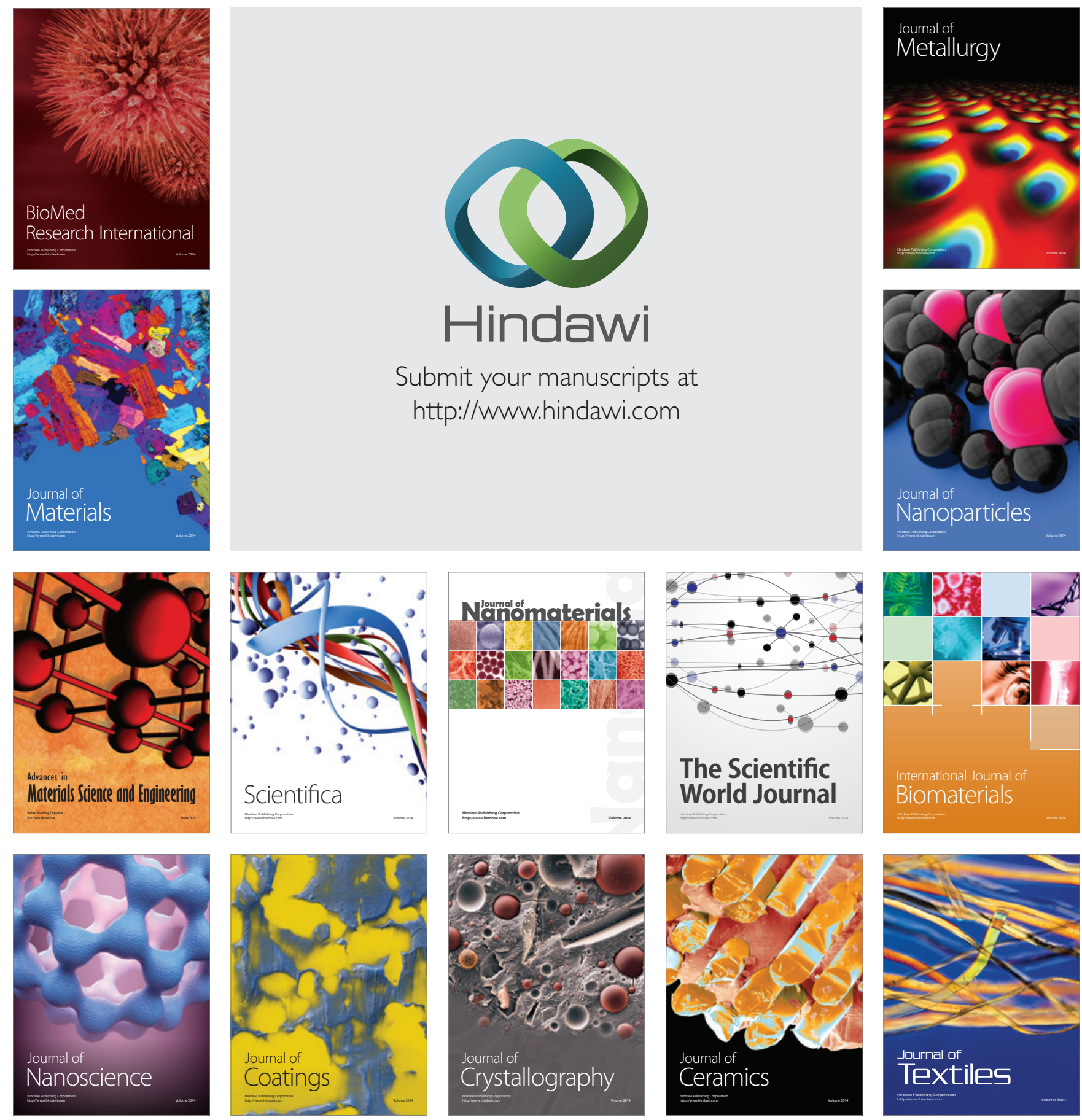